\title{
Trienoic fatty acids and plant tolerance of temperature
}

Oléagineux, Corps Gras, Lipides. Volume 9, Numéro 1, 43-7, Janvier - Février 2002, Dossier : Lipides des plantes

Auteur(s) : Jean-Marc ROUTABOUL, John BROWSE, Laboratoire de biologie des semences, Inra, route de St-Cyr, 78026 Versailles Cedex, France.

Résumé : Les membranes des chloroplastes, siège de la photosynthèse, sont très riches en acides gras tri-insaturés. La proportion de ces acides gras dans les membranes végétales peut être modifiée lors de changements de température. Pour cette raison, il a été postulé que ces acides gras sont impliqués dans les mécanismes de résistance à la chaleur ou au froid des fonctions membranaires, en particulier de la photosynthèse qui est une des fonctions de la cellule les plus sensibles à la température. Afin de tester cette hypothèse, nous avons obtenu un triple mutant d'Arabidopsis qui ne contient pas d'acides gras tri-insaturés et mesuré les effets de la température sur cette lignée. Nous montrons que les acides gras tri-insaturés ne sont pas nécessaires pour la croissance et la photosynthèse dans des conditions normales de température et de lumière. En revanche, ils sont importants pour assurer la biogenèse et le maintien des chloroplastes de plantes cultivées à $4{ }^{\circ} \mathrm{C}$, ou pour la survie de la plante cultivée à $33^{\circ} \mathrm{C}$. La présence de seulement un tiers de ces acides gras est suffisante au maintien d'une croissance et d'une photosynthèse normale si la plante est transférée à une température en dessus ou au-dessous de la normale.

Mots-clés : résistance au froid, thermorésistance, acides gras, lipides, photosynthèse.

Summary : The biophysical reactions of light harvesting and electron transport during photosynthesis take place in a uniquely constructed bilayer, the thylakoid. In all photosynthetic eukaryotes, the complement of atypical glycerolipid molecules that form the foundation of this membrane are characterised by sugar head-groups and a very high level of unsaturation in the fatty acids that occupy the central portion of the thylakoid bilayer. alpha-linolenic (18:3) or a combination of 18:3 and hexadecatrienoic (16:3) acids typically account for approximately two-thirds of all thylakoid membrane fatty acids and over $90 \%$ of the fatty acids of monogalactosyl diacylglycerol, the major thylakoid lipid [1, 2]. The occurrence of trienoic fatty acids as a major component of the thylakoid membrane is especially remarkable since these fatty acids form highly reactive targets for active oxygen species and free radicals, which are often the by-products of oxygenic photosynthesis. Photosynthesis is one of the most temperature-sensitive functions of plant $[3,4]$. There remains a widespread belief that these trienoic fatty acids might have some crucial role in plants to be of such universal occurrence, especially in photosynthesis tolerance of temperature [5]. 


\section{Do plants adapt to temperature by changing the fatty acid composition of their membrane lipids?}

In some desert and evergreen plants, the proportion of trienoic fatty acids in the membrane glycerolipids decreases when plants acclimate to high temperatures [6]. Conversely, cold acclimation in higher plants induces increases in trienoic fatty acid level in leaves [7]. These fatty acid content changes have also been shown to be associated with enhanced chilling or heat tolerance in mutants of Arabidopsis or cyanobacteria [review in: 8-11] and in transformed tobacco plants [12, 13]. For instance, tobacco plants over-expressing the chloroplast ôméga-3 fatty acid desaturase (FAD7) isolated from Arabidopsis contained increased level of 16:3 and 18:3 fatty acids and acquired significant degree of chilling tolerance $[12,13]$. In cyanobacteria mutants, photosynthesis and growth are affected by low temperature only when dienoic fatty acids as well as trienoic fatty acids are eliminated from organisms [14]. Additionally, Murakami et al. [15] recently obtained transgenic tobacco plants in which the gene encoding the chloroplast ôméga-3 fatty acid desaturase (FAD7) was silenced. This tobacco transformant contained reduced level of trienoic fatty acids. Mutant photosynthesis activity was higher after brief high temperature treatments and mutant plants adapted better to high temperature compared to the non-transformed wild type tobacco. These observations led to the proposal that plants may adapt to temperature changes by altering the fatty acid composition of their membrane lipids.

\section{A triple mutant of Arabidopsis contains no detectable trienoic fatty acid in leaf lipids}

Until recently, it has been difficult to study the role of these fatty acids in higher plants because changes in the trienoic fatty acid content obtained either by chemical treatments [16], mutations [10] or transformations $[12,13,15]$ were only limited. In fact, there are two distinct pathways in plant cells for the biosynthesis of glycerolipids and the associated production of polyunsaturated fatty acids [17]. Both pathways are initiated by the synthesis of a 16:0-acyl carrier protein (ACP) in the plastid by the fatty acid synthase. This 16:0-ACP may be elongated to 18:0-ACP and then desaturated to 18:1-ACP by a soluble desaturase so that 16:0-ACP and 18:1-ACP are the primary products of plastid fatty acid synthesis. These products are either used directly in the prokaryotic pathway located in the chloroplast inner envelope for the synthesis of the glycerolipid components of the chloroplast membranes or exported from the chloroplast as CoA thioesters and incorporated into phosphatidylcholine and other lipids in the endoplasmic reticulum by the eukaryotic pathway. In addition, the diacylglycerol moiety of phosphatidylcholine can be returned to the chloroplast envelope and used as a second source of precursors for the synthesis of chloroplast glycerolipids. In each pathway, further desaturation of $16: 0$ and 18:1 occurs only after these fatty acids have been incorporated into the major membrane lipids. In Arabidopsis, three gene products, FAD3, FAD7, and FAD8, mediate the synthesis of trienoic fatty acids from 18:2 and 16:2. The FAD3 gene product is an endoplasmic reticulum desaturase. The FAD7 and FAD8 genes encode two chloroplast isozymes that recognise as a substrate either 18:2 or $16: 2$ attached to any of the chloroplast lipids. A mutation in one of these three genes results in no more than a partial reduction of the trienoic fatty acid content. On its own, the fad 3 mutation reduces the desaturation level of the thylakoid galactolipids only marginally. The fad7 mutation results in a temperature-dependent reduction in the 18:3 and 16:3 content in thylakoid-specific leaf lipids [18], whereas the fatty acid composition of fad8 is indistinguishable from wild type [19]. 
To obtain a more pronounced alteration in the trienoic fatty acid content, it has been necessary to generate multiple mutant lines [20]. A triple mutant line of Arabidopsis, fad3-2 fad7-2 fad8, has been produced that is completely deficient in $18: 3$ and $16: 3$ fatty acids either in the thylakoid or any other membrane of the cell (Figure 1).

Trienoic fatty acids are dispensable for growth and photosynthesis at normal temperatures and modest light levels

To assess the similarities between wild-type and fad3-2 fad7-2 fad8 plants and to lay the basis for investigating growth and photosynthesis of plants at low and high temperatures, we first measured some biochemical and physiological parameters. The fad3-2 fad7-2 fad8 mutant remarkably has morphological, growth, and developmental characteristics similar to those of wild-type Arabidopsis for most of its life cycle when plants are grown at $25^{\circ} \mathrm{C}$. The developing rosette plants were phenotypically similar to the wild type [20]. Metabolic processes, and in particular photosynthesis, did not appear significantly changed (Table 1). The fad3-2 fad7-2 fad8 plants exhibited slight chlorosis due to a $19 \%$ decrease in chlorophyll per unit of fresh weight. The chlorophyll a/b ratio was 3.13 for wild type and 3.49 for the fad3-2 fad7-2 fad8. There was no significant difference in either the membrane lipid content (measured as fatty acids per gram fresh weight) or the protein content of mutant leaves compared with the wild type. Several parameters calculated from chlorophyll a fluorescence have proven useful in comparing the photosynthetic capabilities of plants. In particular, $\mathrm{Fv} / \mathrm{Fm}$ is an estimate of the maximal quantum yield of PSII photochemistry in dark-adapted leaves [21]. This parameter describes the efficiency of the electron transfer within PSII. $\mathrm{PHI}_{\|}$is the quantum yield of linear electron transfer [22] measured at steady state under ambient light levels. This parameter measures PSII quantum yield but reflects the efficiency of the whole photosynthetic process because PSII is coupled to downstream processes (including PSI and $\mathrm{CO}_{2}$ assimilation) in the light. At $25^{\circ} \mathrm{C}$, there were no major differences between the wild type and fad3-2 fad7-2 fad 8 mutant in either of these fluorescence parameters (Table 1). At $22^{\circ} \mathrm{C}$, the $\mathrm{CO}_{2}$ and light-saturated rates of $\mathrm{CO}_{2}$ fixation by wild-type and mutant plants were indistinguishable at $32.1 \pm 1.9$ and $32.6 \pm 2.1$ mumol $\mathrm{CO}_{2}$ $\mathrm{m}^{-2} \mathrm{~s}^{-1}$, respectively (M.E. Poulson, J.-M. Routaboul, G.E. Edwards, J. Browse, unpublished data). Whole-chain, PSII or PSI-dependent oxygen evolutions in isolated thylakoids were also identical in both wild type and mutant (Table 1). Taken as a whole, these data demonstrate that trienoic fatty acids are substantially dispensable for growth and photosynthesis at normal temperatures and modest light levels.

\section{Trienoic fatty acids are required to maintain chloroplast function at low temperature}

To compare the in vivo behaviour of the wild-type and fad3-2 fad7-2 fad8 photosynthetic membranes at low temperatures, we recorded the fluorescence characteristics of detached leaves during short exposure to a range of temperatures from $25^{\circ} \mathrm{C}$ to $5^{\circ} \mathrm{C}$. Typically, the values of both $\mathrm{F}_{\mathrm{v}} / \mathrm{F}_{\mathrm{m}}$ and $\mathrm{PHI}_{\|}$are decreased when the temperature is lowered. The more rapid decline of $\mathrm{PH} \|_{\|}$ compared with $F_{v} / F_{m}$ shows that plant leaves exposed to below-normal temperatures exhibited a progressive decrease in their photosynthetic electron transfer capabilities. When the electron transfer is limited, the photosystem components become more completely reduced and $\mathrm{PHI}_{\|}$ declines. In the fad3-2 fad7-2 fad8 mutant, this cold response was qualitatively similar but quantitatively stronger, compared to the wild type [23]. For instance, $1.5 \mathrm{hr}$ at $5^{\circ} \mathrm{C}$ caused a $46 \%$ inhibition of $\mathrm{PHI}_{\|}$in mutant (compared to the same measurement at $25^{\circ} \mathrm{C}$ ), whereas the same 
temperature treatment induced a more limited inhibition (39\%) in the wild type. Although this differential effect of low temperature on $\mathrm{PHI}_{\|}$of the mutant was consistently reproducible in several series of experiments, it was not possible to demonstrate a consistent difference in $\mathrm{CO}_{2}$ gas exchange rates between wild-type and fad3-2 fad7-2 fad8 plants measured at $10^{\circ} \mathrm{C}$ (M.E Poulson, J.-M. Routaboul, G.E. Edwards and J. Browse, unpublished results). Thylakoid preparations from wild-type and mutant plants assayed for whole chain electron transport at $10^{\circ} \mathrm{C}$ also failed to demonstrate a significant effect (J.-M. Routaboul and J. Browse, unpublished results). Both techniques are relatively insensitive at low temperatures but together with the data from fluorescence analysis, they demonstrate that temperatures as low as $5^{\circ} \mathrm{C}$ have only subtle effects on photosynthetic processes of the mutant relative to wild type.

Although low temperatures had little effect on photosynthesis of fad3-2 fad7-2 fad8 plants in the short term, prolonged incubation of mutant plants at $4^{\circ} \mathrm{C}$ revealed a very different mutant phenotype [23]. After as little as 10 days at $4^{\circ} \mathrm{C}$, newly developed leaf tissue of mutant plants exhibited chlorosis, which was not evident in wild-type controls. The degree and extent of chlorosis became progressively more pronounced in mutant plants as the low-temperature treatment continued. After 30 days at $4^{\circ} \mathrm{C}$ most leaves on the mutant plants were pale green and the plants were noticeably smaller than wild-type controls. Measurements of chlorophyll content showed that both mutant and wild-type plants lost chlorophyll at the beginning of the $4^{\circ} \mathrm{C}$ treatment so that plants of both genotypes contained $30 \%$ less chlorophyll after 10 days. After this initial loss, the chlorophyll content of the wild type increased again while the chlorophyll content of the mutant continued to decline throughout the cold treatment. Measurements of $\mathrm{F}_{\mathrm{v}} / \mathrm{F}_{\mathrm{m}}$ and $\mathrm{PHI}_{\|}$on leaves sampled from $4^{\circ} \mathrm{C}$-grown plants and assayed at $25^{\circ} \mathrm{C}$ showed that the chlorophyll loss was accompanied by a decline in photosynthetic efficiency (Figure 2). In particular, $\mathrm{PHI}_{\|}$fell steadily throughout the experiment to reach $53 \%$ of the starting value after 30 days. By contrast, $F_{v} / F_{m}$ showed relatively little change during the first 5 to 10 days at $4^{\circ} \mathrm{C}$ and had declined by less than $25 \%$ by 30 days.

These changes in photosynthetic performance and chlorophyll content were accompanied by extensive changes in chloroplast ultrastructure in the mutant. Before transfer to low temperature, the thylakoid structure and organisation of mutant chloroplasts were substantially similar to wild type. Wild-type chloroplasts retained this structure even after 30 days at $4^{\circ} \mathrm{C}$. However, the same treatment resulted in extensive loss of thylakoids from fad3-2 fad7-2 fad8 chloroplasts and a marked reduction in stacked membranes [23].

Despite their chlorotic appearance and altered chloroplast ultrastructure, fad3-2 fad7-2 fad8 plants, after 30 days at $4^{\circ} \mathrm{C}$, retained a substantial capacity for recovery. Four days after being returned to $22^{\circ} \mathrm{C}$, mutant plants had chlorophyll contents that were $75 \%$ of pre-treatment values and more than $90 \%$ of wild-type controls [23]. We have successfully maintained mutant plants for three months at $4^{\circ} \mathrm{C}$. At the end of this time, the fresh-weight of the mutants averaged less than $35 \%$ of that of wildtype controls.

The fad7-1 allele contains a leaky mutation that, on the basis of leaf fatty acid composition, retains a small amount of the FAD7 desaturase activity [19]. The availability of this allele has allowed us to produce plants with very low levels of $16: 3$ and 18:3 fatty acids [20]. When a collection of these plants and other mutants were incubated at $4^{\circ} \mathrm{C}$ for 30 days, there was a clear correlation between 
the severity of chlorosis and the proportion of $16: 3$ plus 18:3 fatty acids in leaves of the different plants. When leaves were detached, warmed to $25^{\circ} \mathrm{C}$, and subjected to fluorescence analysis, this correlation was extended to both $\mathrm{PHI}_{\|}$and $\mathrm{F}_{\mathrm{v}} / \mathrm{F}_{\mathrm{m}}$ measurements [23]. Our data suggest that $\mathrm{PHI}_{\|}$(as well as the visual appearance of plants growing at $4^{\circ} \mathrm{C}$ ) can be maintained at wild-type levels by 15 to $20 \%$ trienoic fatty acids in the leaf membranes even though leaves of wild-type plants contain more than $60 \%$ of these fatty acids.

\section{Trienoic fatty acids are required for plant survival at high temperature}

Temperatures higher than $35^{\circ} \mathrm{C}$ inhibit photosynthesis [4] even though light has been shown to protect photosynthesis from heat [24-26]. To assess the effects of high temperatures and light on the photosynthetic machinery, we incubated detached leaves from wild type and triple mutant fad3-2 fad7-2 fad8 Arabidopsis at $40^{\circ} \mathrm{C}$. Then, the quantum efficiency of photosynthesis was monitored either in the dark, by measuring the fluorescence parameter $\mathrm{F}_{\mathrm{v}} / \mathrm{F}_{\mathrm{m}}$, or in the light by measuring $\mathrm{PHI}_{\|}$ under physiological light levels (PFD of 100 mumol quanta $\mathrm{m}^{-2} \mathrm{~s}^{-1}$ ). Figure 3 shows that both wild type and fad3-2 fad7-2 fad8 mutant photosynthetic capabilities significantly diminished when leaves were incubated at $40^{\circ} \mathrm{C}$ in the dark. However, the mutant PSII tolerated high temperatures better than the wild type. To obtain a $50 \%$ decrease in $F_{v} / F_{m}$, it was necessary to heat wild-type leaves at $40^{\circ} \mathrm{C}$ for only $15 \mathrm{~min}$ whereas leaves from the mutant only reached this level after $40 \mathrm{~min}$ of heat treatment. Similarly, PSII-dependent oxygen evolutions in isolated thylakoids were also higher in mutant compared to wild-type after brief exposure to high temperature in the dark (result not shown). However, extended incubation at $40^{\circ} \mathrm{C}$ in the light (which is a condition likely to occur during heat stress) did not reduce $\mathrm{PHI}_{\|}$below $90 \%$ of the starting value in leaves of either the wild type or the mutant.

Notwithstanding these observations, acclimation of plants to $33^{\circ} \mathrm{C}$ resulted in differences in the appearance of plants and their relative growth measured as the fresh weight of aerial plants (Figure 4). The relative growth was lower in mutant plants than in wild-type controls after only three days of treatment. After 8 days, mutant plants stopped growing, leaves began to wilt and to dry. The plant ultimately died after 15 days. Our initial experiments indicate that the absence of trienoic fatty acids stabilizes PSII against heat treatment applied in the dark. In order to determine whether these observations are related in acclimated plants, we randomly harvested leaves during growth $a 3^{\circ} \mathrm{C}$, cooled them to $25^{\circ} \mathrm{C}$ for $1 \mathrm{hr}$ in the dark and then determined Fv/Fm (the same result were obtained measuring $\left.\mathrm{PHI}_{\|}\right)$. At this temperature, wild-type controls photosynthetic efficiency was not affected whereas the quantum yield of PSII electron transport of triple mutant was at first slightly inhibited from 6 to 9 days but decreased thereafter to reach 34 and $11 \%$ of the initial value after respectively 11 and 13 days at $33^{\circ} \mathrm{C}$. Thus, the fatty acid deficiency did not improve the photosynthetic capabilities of mutant plants transferred to high temperature and was critical for plant growth.

To exclude the possibility that the triple mutant line coincidentally contained an additional mutation (at a locus other than the fad loci) that would be responsible for this phenotype, we also examined the single mutants fad3-2, fad7-2, fad8 and the double mutant fad7-2fad8 after transfer at $33^{\circ} \mathrm{C}$. After 15 days, only the triple mutant plants died. The growth of fad 3 appeared to be slightly reduced compared to fad7-2, fad8 and a few fad3-2 plants may eventually died at the end of the 15-day period. The double mutant fad7-2fad8 grew slightly better than wild-type plants.

These observations indicate that it is the biochemical defect in polyunsaturated lipid synthesis that is 
the cause of the high temperature phenotype reported here. The fad7-2fad 8 mutant lacks only the chloroplast-localised ôméga-3 desaturases and contains about 17\% linolenic acid (18:3). Thus, linolenic acid would seem to be essential for the establishment of plant resistance to high temperature.

\section{CONCLUSION}

A surprising finding during the initial isolation and characterisation of the fad3-2 fad7-2 fad8 line was that triple mutant plants lacking trienoic fatty acids were indistinguishable from wild type in vegetative growth and development at $22^{\circ} \mathrm{C}$ [20]. The more detailed analyses reported here of the fluorescence and electron transport characteristics of mutant plants confirm that 18:3 and 16:3 fatty acids are essentially dispensable for photosynthetic processes at $25^{\circ} \mathrm{C}$ under our growth and measurement conditions. Similarly, direct effects of short temperature treatments on mutant photosynthesis seem to be limited.

In contrast, trienoic fatty acids appear to be essential for growth at temperature under or below normal. They are important to ensure the correct biogenesis and maintenance of chloroplasts during growth of plants at $4^{\circ} \mathrm{C}$ and are critical for plant growth at $33^{\circ} \mathrm{C}$. Low and high temperature-grown plants show a distinct pattern of symptoms. For this reason, we believe that different mechanisms of low or high temperature damages are operating in the mutant, even though they all depend of a common trienoic fatty acid change. It has been suggested that the fatty acid changes primarily affect processes in chloroplast biogenesis because tissue that had developed at $22^{\circ} \mathrm{C}$ before transfer to low temperature did not become chlorotic or show changes in chloroplast ultrastructure $[27,28]$. In principle, a partial defect in transport of proteins through the chloroplast envelope, or into or through the thylakoid membrane, could explain such a phenotype. During chloroplast biogenesis, when protein transport is maximal, even a partial defect could have severe consequences. Transport processes remain important for maintenance of the mature chloroplast, but the quantitatively lower demands on the transport machinery might be met despite the defect. Under such a scenario, a more severe defect would produce large effects on new tissue and also begin to compromise maintenance processes in the mature chloroplasts of older tissue. Moreover, we found that photosynthetic capabilities and growth rate decreased concomitantly in the triple mutant during growth at above normal temperature. Thus, mutant plant survival at high temperature may be related to the thermotolerance capabilities of photosynthesis. However, we cannot rule out that other biochemical factors associated with the thylakoid membranes are responsible for the death of triple mutant plants grown at high temperature. On this line, linolenic acid is a precursor of jasmonic acid that is involved in many plant responses $[29,30]$.

The nature of the effects seems also to depend on a specific species that is deficient rather than through the mediation of global changes in membrane fluidity or integrity in the mutant. Approximately one-third of trienoic fatty acids is sufficient to maintain normal photosynthetic function and growth at either lower or higher than normal temperatures.

The triple mutant fad3-2 fad7-2 fad8 allow us to show that the relationship between trienoic fatty acids and temperature tolerance in plants is more complex that originally thought and most probably involved different and specific mechanisms. A better understanding of such a relationship is a prerequisite for engineering plants with better tolerance of temperature. 


\section{Acknowledgements}

This work was supported by the US National Science Foundation (Grant No. IBN-9407902). We thank $\operatorname{Dr} \mathrm{M}$. Miquel for critical reading of the manuscript.

\section{REFERENCES}

1. DOUCE R, JOYARD J (1982). Plants galactolipids. In: PK Stumpf, EE Conn, eds. The biochemistry of plants. New York: Academic Press: 331-2.

2. HARWOOD JL (1982). Plant acyl lipids. In: PK Stump, EE Conn, eds. The biochemistry of plants, New York: Academic Press: 1-55.

3. WEIS E, BERRY JA (1988). Plants and temperature. In: Long PS and Woodmard FI, eds. Cambridge: Company of Biologists: 329-46.

4. BERRY J, BJÖRKMAN O (1980). Photosynthetic response and adaptation to temperature in higher plants. Ann Rev Plant Physiol Plant Mol Biol, 31: 491-543.

5. WEBB MS, GREEN BR (1991). Biochemical and biophysical properties of thylakoid acyl lipids. Biochim Biophys Acta, 1060: 133-58.

6. PEARCY RW (1978). Effect of growth temperature on the fatty acid composition of the leaf lipids in Atriplex lentiformis (Torr.) Wats. Plant Physiol, 61: 484-6.

7. RAISON JK, ROBERTS JKM, BERRY JA (1982). Correlations between the thermal stability of chloroplast (thylakoid) membranes and the composition and fluidity of their polar lipids upon acclimation of the higher plant Nerium oleander to growth temperature. Biochim Biophys Acta, 688: 218-28.

8. GRAHAM D, PATTERSON BD (1982). Response of plants to low non-freezing temperatures: proteins, metabolism and acclimation. Annu Rev Plant Physiol Plant Mol Biol, 33: 347-72.

9. MURATA N, WADA H (1995). Acyl-lipid desaturases and their importance in the tolerance and acclimatization to cold of Cyanobacteria. Biochem J, 308: 1-7.

10. VIJAYAN P, ROUTABOUL JM, BROWSE J (1998). A genetic approach to investigating membrane lipid structure and photosynthetic function. In: Murata N, Siegenthaler PA, Govindjee, eds. Advances in photosynthesis, lipids in photosynthesis: structure, function and genetics. Dordrecht, the Netherlands: Kluwer Academic Publishers: 220-3.

11. TOKUHISA J, BROWSE J (1999). Genetic engineering of plant chilling tolerance. Genet Eng, 21: 7993.

12. KODAMA H, HAMADA T, HORIGUCHI G, NISHIMURA M, IBA K (1994). Genetic enhancement of cold tolerance by expression of a gene for chloroplast ôméga-3 desaturase in transgenic tobacco. Plant Physiol, 105: 601-5. 
13. KODAMA H, HORIGUCHI G, NISHIUCHI T, NISHIMURA M, IBA K (1995). Fatty acid desaturation during chilling acclimation is one of the factor involved in conferring low-temperature tolerance to young tobacco leaves. Plant Physiol, 107: 1177-85.

14. TASAKA Y, GOMBOS Z, NISHIYAMA Y, et al. (1996). Targeted mutagenesis of acyl-lipid desaturases in synechocystis: evidence for the important roles of polyunsaturated membrane lipids in growth, respiration and photosynthesis. EMBO J, 15: 6416-25.

15. MURAKAMI Y, TSUYAMA M, KOBAYASHI Y, KODAMA H, IBA K (2000). Trienoic fatty acid and plant tolerance of high temperature. Science, 287: 476-9.

16. THOMAS PG, DOMINY PJ, VIGH L, MANSOURIAN AR, QUINN PJH, WILLIAMS PW (1986). Increased thermal stability of pigment-protein complexes of pea thylakoids following catalytic hydrogenation of membrane lipids. Biochim Biophys Acta, 849: 131-40.

17. BROWSE J, SOMERVILLE C (1991). Glycerolipid synthesis: biochemistry and regulation. Ann Rev Plant Physiol Plant Mol Biol 42: 467-506.

18. BROWSE JA, MCCOURT PJ, SOMERVILLE CR (1986). A mutant of Arabidopsis deficient in $\mathrm{C}_{18: 3}$ and $C_{16: 3}$ leaf lipids. Plant Physiol, 81: 859-64.

19. McCONN M, HUGLY S, SOMERVILLE C, BROWSE J (1994). A mutation at the fad8 locus of Arabidopsis identifies a second chloroplast ôméga-3 desaturase. Plant Physiol, 106: 1609-14.

20. McCONN M, BROWSE J (1996). The critical requirement for linolenic acid is for pollen development, not photosynthesis, in an Arabidopsis mutant. Plant Cell, 8: 403-16.

21. KITAJIMA M, BUTLER WL (1975). Quenching of chlorophyll fluorescence and Primary photochemistry in chloroplasts by dibromothyquinone. Biochim Biophys Acta, 376: 105-15.

22. GENTY B, BRIANTAIS JM, BAKER NR (1989). The relationship between the quantum yield of photosynthetic electron transport and quenching of chlorophyll fluorescence. Biochimica Biophysica Acta, 990: 87-92.

23. ROUTABOUL JM, FISCHER S. AND BROWSE J (2000). Trienoic fatty acids are required to maintain chloroplast function at low temperatures. Plant Physiol, 124: 1697-705.

24. WEIS E (1981). The temperature-sensitivity of dark-inactivation and light-activation of the ribulose-1,5-bisphosphate carboxylase in spinach chloroplasts. FEBS letters, 129: 197-200.

25. KISLYUK IM (1979). Protecting and injurious effects of light on photosynthetic apparatus during and after heat treatment of leaves. Photosynthetica, 13: 386-91.

26. SCHREIBER U, BERRY JA (1977). Heat-induced changes of chlorophyll fluorescence in intact leaves correlated with damage of the photosynthetic apparatus. Planta, 136: 233-8.

27. HUGLY S, SOMERVILLE C (1992). A role for membrane lipid polyunsaturation in chloroplast biogenesis at low temperature. Plant Physiol, 99: 197-202. 
28. JARVIS P, CHEN LJ, LI H, PETO CA, FANKHAUSER C, CHORY J (1998). An Arabidopsis mutant defective in the plastid general protein import apparatus. Science, 282: 100-3.

29. WIERSTRA I, KLOPPSTECH K (2000). Differential effects of methyl jasmonate on the expression of the early light-inducible proteins and other light-regulated genes in barley. Plant Physiol, 124: 83344.

30. HOWE GA (2001). Cyclopentenone signals for plant defense: remodeling the jasmonic acid response. Proc Natl Acad Sci USA, 98: 12317-9.

Illustrations

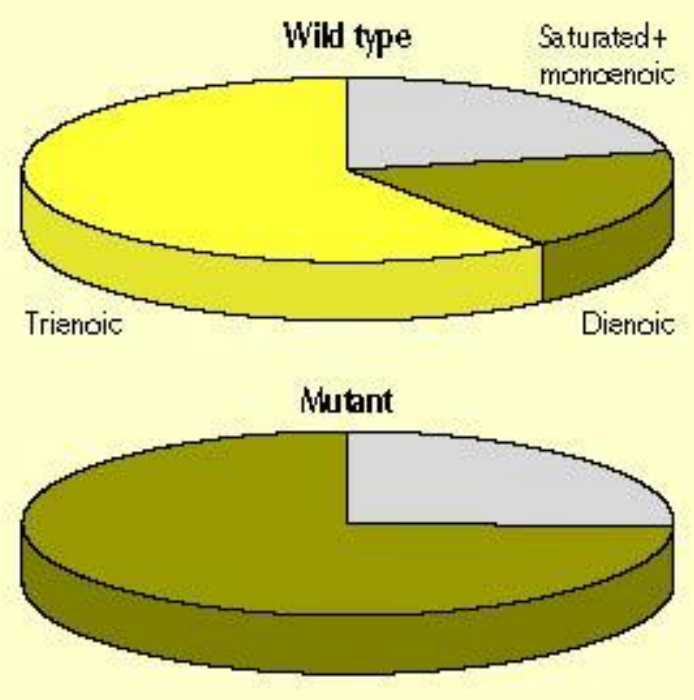

Figure 1. Total fatty acid composition of wild-type and mutant leaver. The values are the means of ten independent measurements. 


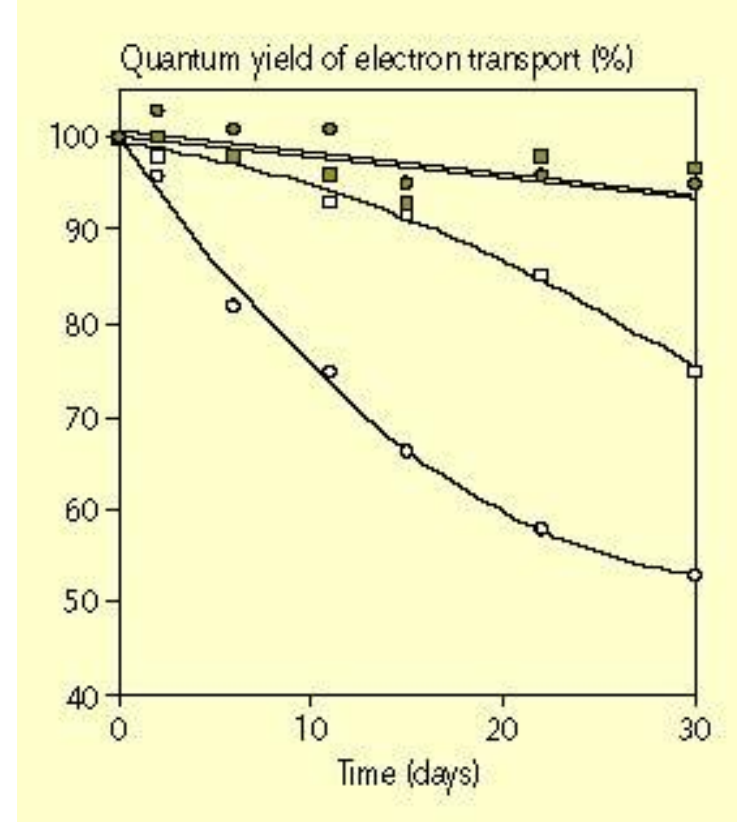

Figure 2. Effect of long-term exposure to $4^{\circ} \mathrm{C}$ on photosynthesis of wild-type (closed symbols) and fad3-2 fad7-2 fad8 mutant (open symbols) Arabidopsis. Data shown are for $F / F_{m}\left(\mathbf{Q},()\right.$ and $w_{n i n}(\mathbf{\bullet}, 0)$. Plants were grown at $22^{\circ} \mathrm{C}$ for 13 days prior to transfer to $4^{\circ} \mathrm{C}$. During low-temperature treatment, detached leaves were rewarmed to $25^{\circ} \mathrm{C}$ for $1 \mathrm{hr}$ in the dark and then $\mathrm{F} / \mathrm{F}_{\mathrm{m}}$ and $\mathrm{s}_{\text {if }}$ were measured at $25^{\circ} \mathrm{C}$. Results are expressed as percentage of pretreatment values. Values are means $\pm S E$ of 5 leaves. Pretreatment values for wild type were $F / F_{\mathrm{m}}=0.761 \pm 0.004 ; F_{i f}=0.553 \pm 002$; and for $\mathrm{fad} 3-2 \mathrm{fad} 7-2 \mathrm{fad} 8$ were $F_{v} / F_{\mathrm{m}}=0.768 \pm 001 ; \Phi_{\mathrm{fi}}=0.551 \pm 001$. 


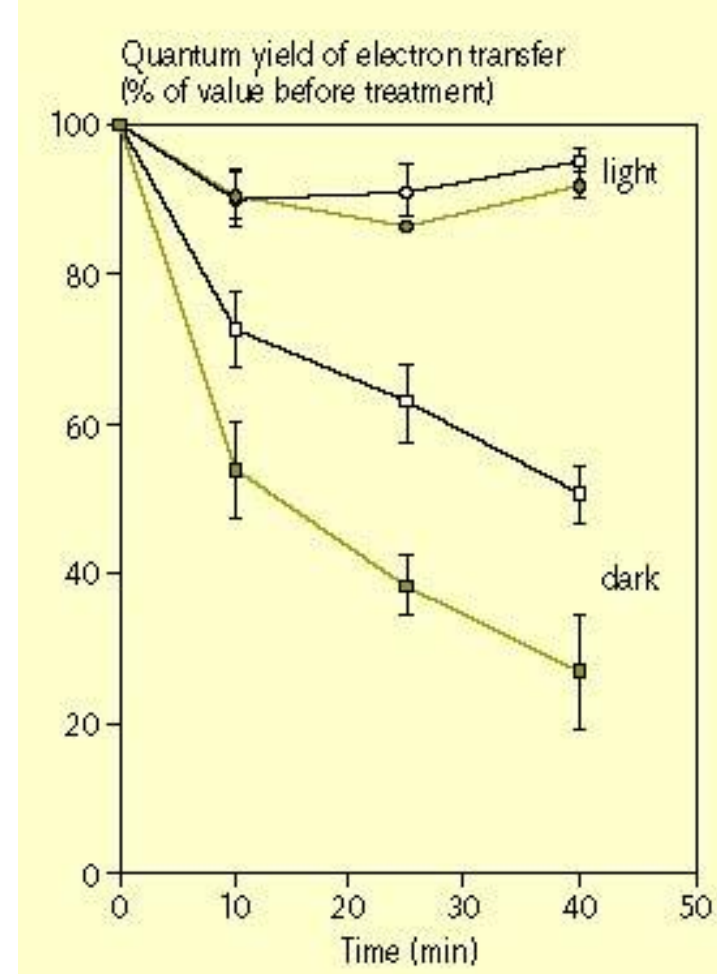

Figure 3. Effect of high temperature on fad $3-2 \mathrm{fad} 7-2 \mathrm{fad} 8$ mutant (open symbols) and wild-type (closed symbols) photosynthesis. Leaves were incubated at $40^{\circ} \mathrm{C}$ and the inhibition of photosynthesis were mo ritored at a constant PFD of 100 fimol quanta $m^{-2} s^{-1}$ by $w_{i n}(\mathbf{0}, O)$ and in the dark by $F / F_{m}(\mathbf{n},()$. Values are means $\pm S E(n=5)$. 


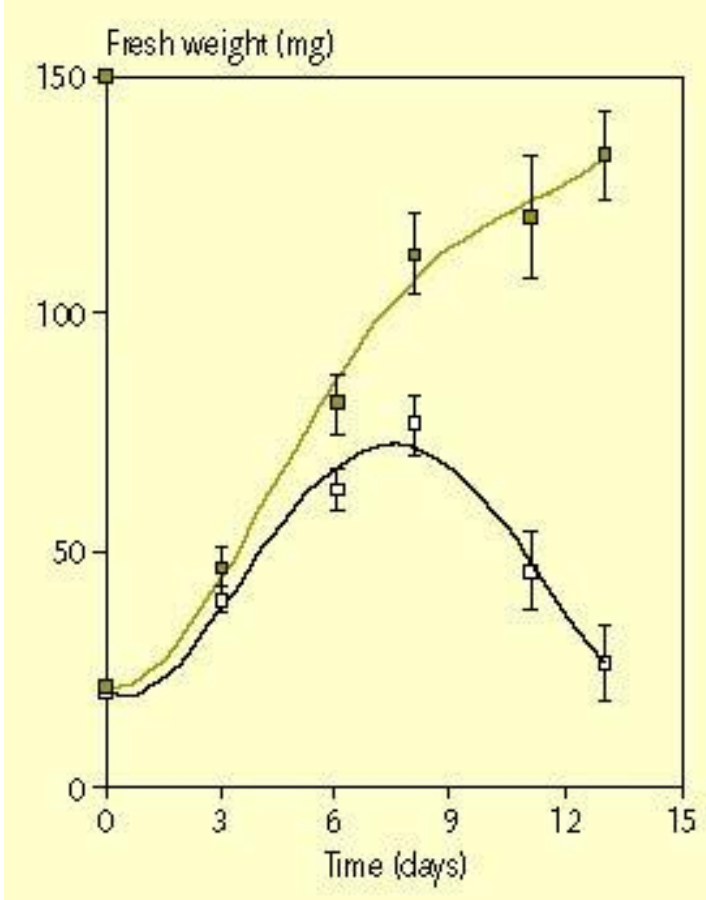

Figure 4. The effects of high temperature on growth of wild-type (closed symbot) and fad 3-2 fad7-2 fad 8 mutant (open symbo/s) Arabido pis plants transferred to $33^{\circ} \mathrm{C}$. MeantSE $(n=5)$ of aerial fresh weight.

Table 1. Comparison of the relative amounts of chlorophyll, fatty acids, and protein toget her with fluorescence parameters in leaves and axygen evolution measurements in isolated thylakoid for wild type and mutart. Plants were gown at $22^{\circ} \mathrm{C}$ and under continuous illumination of 125 imo $/ \mathrm{m}^{-2} \mathrm{~s}^{\prime}$. Measurements were made at $25^{\circ} \mathrm{C}$. Values are meanstSE of 25 leaves from five independent experiments for fluorescence parameters and from thee measurements on a single representative preparation of isolated thylako ids.

\begin{tabular}{|c|c|c|}
\hline & Wild type & $\mathrm{fad} 3-2 \mathrm{fad} 7-2 \mathrm{fad} 8$ \\
\hline Chbrophyll a/b ratio & $3.13+0.07$ & $3.49 \pm 0.08$ \\
\hline Total chbrophyll (mg.g $\mathrm{g}^{-1}$ fresh wt) & $1.64 \pm 0.10$ & $1.33 \pm 0.09$ \\
\hline Protein (mg. $g^{-1}$ fresh wt) & $24.55 \pm 1.40$ & $22.15 \pm 1.80$ \\
\hline Fatty acids ( $\mu g \cdot g^{-1}$ fresh wt) & $6.29 \pm 0.65$ & $6.26 \pm 0.28$ \\
\hline$F_{\sqrt{ }} / F_{m}$ & $0.759 \pm 0.005$ & $0.769 \pm 0.005$ \\
\hline$\Phi_{\|}$ & $0.575 \pm 0.007$ & $0.578 \pm 0.007$ \\
\hline Whole chain activity $\left(\mu \mathrm{mol} \mathrm{O}_{2} \mathrm{~h}^{-1} \mathrm{mg}^{-1} \mathrm{chl}\right)$ & $197 \pm 11$ & $194 \pm 12$ \\
\hline PSIl activity $\left(\mu \mathrm{mol} \mathrm{O}_{2} \mathrm{~h}^{-1} \mathrm{mg}^{-1} \mathrm{chl}\right)$ & $300 \pm 20$ & $282 \pm 25$ \\
\hline PSl activity $\left(\mu \mathrm{mol} \mathrm{O}_{2} \mathrm{hr}^{-1} \mathrm{mg}^{-1} \mathrm{chl}\right)$ & $276 \pm 19$ & $282 \pm 19$ \\
\hline
\end{tabular}

